\title{
Editorial
}

This special issue includes the main results of studies concentrating around the topic: Treatment of Non-linear Systems in Physics and Economics elaborated by the group of scientists from the Russian Research Center "Kurchatov Institute", Moscow, Russia directed by Eugene P. Velikhov, President of the Russian Research Center "Kurchatov Institute", Moscow, Russia. In a wider sense this topic reflects the issue: Search for Absolute Values and Unity in the Science.

The reason and the justification of inclusion of results of this group in our journal are very natural: these papers represent the attempt to transfer the scientific principles erasing from non-linear approaches in Physics to the deepness of complexity of biological systems and to the better understanding of social and societal processes. The space-time discreteness of the presented non-linear phenomena plays the essential role in the presented results.

We also hope that such a publication will support the continuity of the fruitful scientific contacts between Russian scientists and the international scientific community.
VLADIMIR GONTAR MICHAEL SONIS 


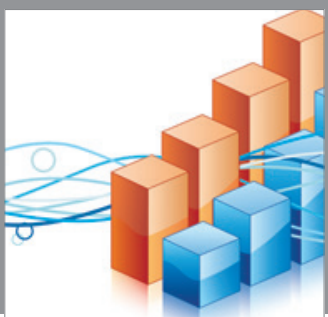

Advances in

Operations Research

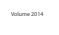

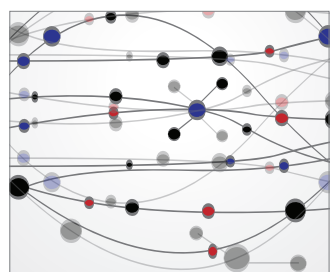

\section{The Scientific} World Journal
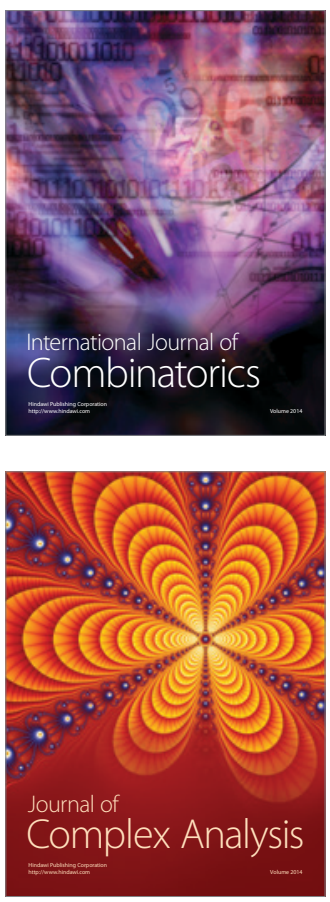

International Journal of

Mathematics and

Mathematical

Sciences
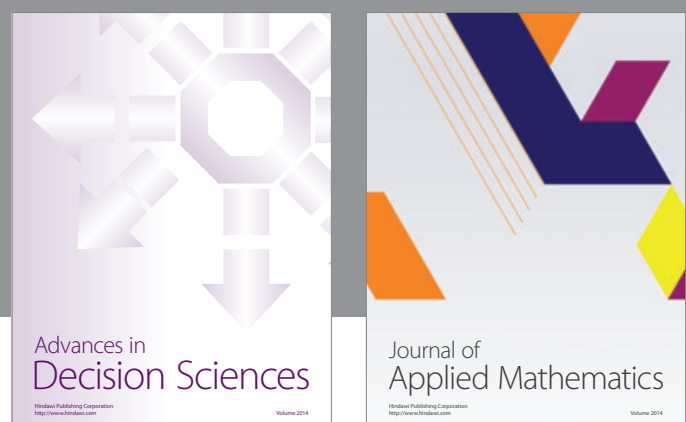

Journal of

Applied Mathematics
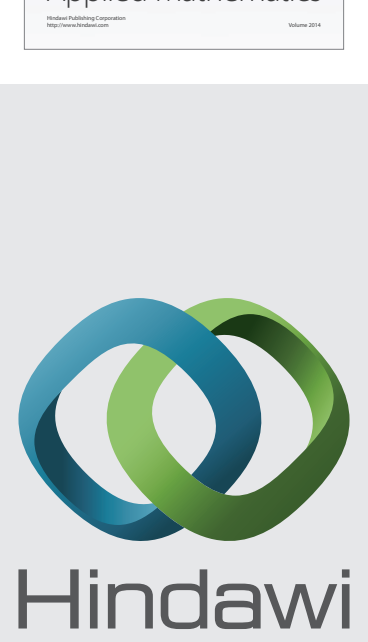

Submit your manuscripts at http://www.hindawi.com
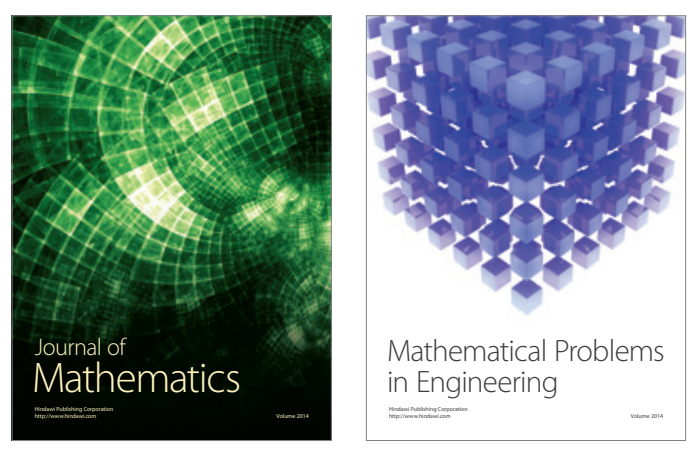

Mathematical Problems in Engineering
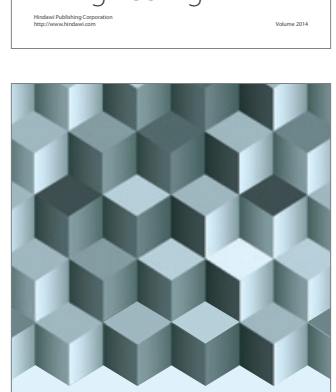

Journal of

Function Spaces
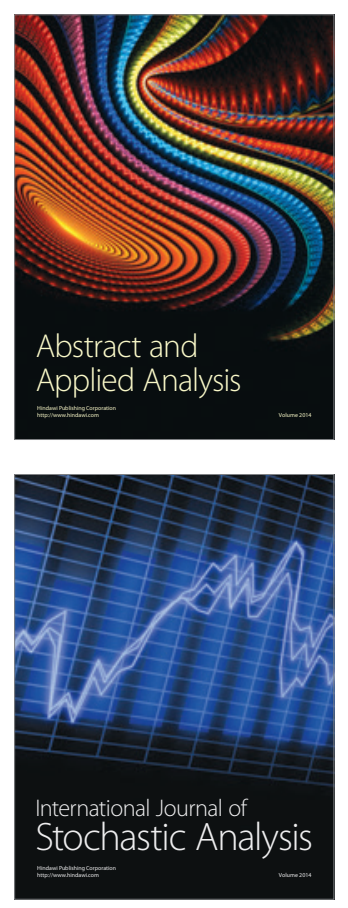

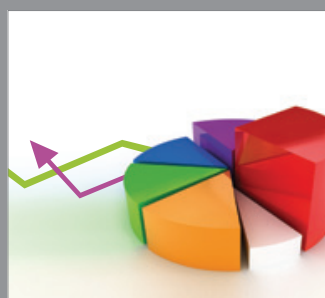

ournal of

Probability and Statistics

Promensencen
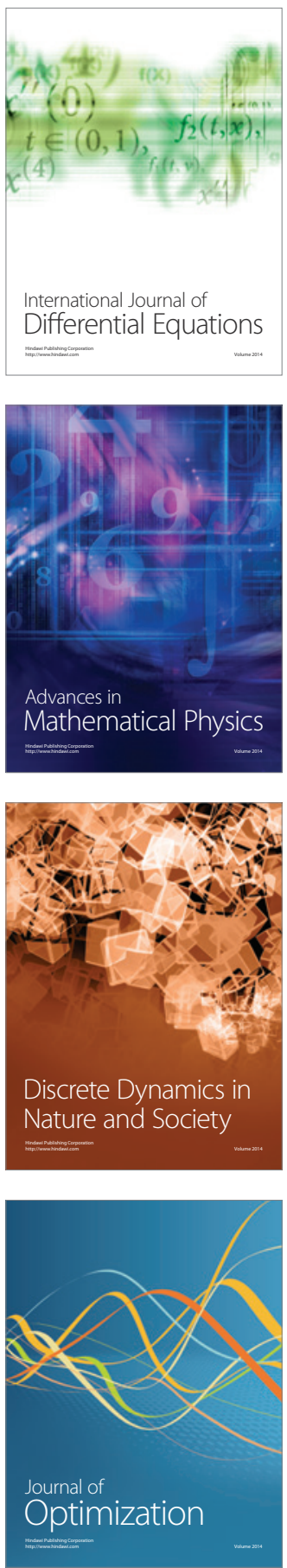